\title{
Evaluation of the intercanine distance in newborns with cleft lip and palate using 3D digital casts
}

\author{
Bianca Zeponi Fernandes MELLO1, Viviane Mendes FERNANDES², Cleide Felício Carvalho CARRARA², Maria \\ Aparecida Andrade Moreira MACHADO ${ }^{3}$, Daniela Gamba GARIB ${ }^{4}$, Thais Marchini OLIVEIRA ${ }^{4}$ \\ 1- Bauru School of Dentistry, University of São Paulo, Bauru, SP, Brazil. \\ 2- Hospital for Rehabilitation of Craniofacial Anomalies, University of São Paulo, Bauru, SP, Brazil. \\ 3- Department of Pediatric Dentistry, Orthodontics and Community Health, Bauru School of Dentistry, University of São Paulo, Bauru, SP, Brazil. \\ 4- Department of Pediatric Dentistry, Orthodontics and Community Health, Bauru School of Dentistry and Hospital for Rehabilitation of Craniofacial Anomalies, \\ University of São Paulo, Bauru, SP, Brazil.
}

Corresponding address: Thais Marchini Oliveira - Faculdade de Odontologia de Bauru - Universidade de São Paulo - Alameda Dr. Octávio Pinheiro Brisolla, 9-75 - Bauru, São Paulo - 17012-901 - Brazil - Phone: 551432358224 - e-mail: marchini@usp.br

Submitted: January 22, 2013 - Modification: May 26, 2013 - Accepted: August 13, 2013

\section{ABSTRACT}

\begin{abstract}
O bjective: The purpose of this present study was to compare, by means of 3D digital casts, the anterior transverse dimension of the dental arch of newborns with and without cleft lip and palate. Material and Methods: The sample was composed of ninetyfour children aged from 3 to 9 months divided into three study groups: Group I - children without craniofacial deformities (control group); Group II - children with unilateral cleft lip and palate; Group III - children with bilateral cleft lip and palate. Impressions were executed before lip and palate repair in patients with clefts. Dental casts were digitized using a 3D scanner linked to a computer. Measurements of the intercanine distance were measured on the digital casts. Intergroup comparisons were performed using ANOVA $(p<0.05)$. Results: The results showed a mean of $36.5 \mathrm{~mm}$ for unilateral cleft lip and palate group, $34.8 \mathrm{~mm}$ for bilateral cleft lip and palate group and $27.52 \mathrm{~mm}$ for the control group. There was a statistically significant difference between the control group and both groups of patients with cleft lip and palate. There was no statistically significant difference between complete unilateral and bilateral cleft lip and palate groups. Conclusions: Patients with complete cleft lip and palate were born with an increased anterior dimension of the maxillary dental arch compared to non cleft patients.
\end{abstract}

Keywords: Dental arch. Cleft lip. Cleft palate. Anatomic landmarks. Casts.

\section{INTRODUCTION}

Cleft lip and palate is a relatively common craniofacial malformation with variable phenotypes ${ }^{12}$. The clefts occur between the $4^{\text {th }}$ and $12^{\text {th }}$ weeks of intrauterine life, period during which the embryonic development of the face and palate are taking place ${ }^{8}$. Maxillary hypoplasia and mid face retrusion are frequent findings in patients with cleft lip and palate. A widely accepted etiology for the occurrence of maxillary retrusion has been the iatrogenic effects of surgical interventions, creating lip tension and scar tissue surrounding the palate and maxilla, resulting in the growth disturbance ${ }^{12}$.

The treatment of cleft lip and palate is a difficult process, which should be initiated soon after birth and continue up to adulthood, requiring the participation of an interdisciplinary team ${ }^{7}$. The morphological rehabilitation of clefts involves lip plastic surgery at 3 months of age and palate plastic surgery around 1 year of age, as well as secondary alveolar bone graft performed between 9 and 12 years of age $\mathrm{g}^{7}$. Additionally to the primary plastic surgeries, the rehabilitation requires an interdisciplinary protocol involving different specialties as speech and language therapy, maxillofacial surgery and oral rehabilitation so that the therapeutic procedures should be standardized?

The fact that the clinician is aware of the dimensional alterations of the dental arches occurring in cleft lip and palate subjects is of extreme therapeutic interest, because it can influence on the stability of the results obtained 
in the rehabilitation of the individual. The clinician should not only aim the rehabilitation of the patients but also their social inclusion. The rehabilitation process involves the action of an interdisciplinary team within a relationship of reciprocity, mutuality and dialogue. In this relationship, the collaboration among several areas has a fundamental role ${ }^{8}$. The ideal rehabilitative treatment is still a problem, and in many areas there are several protocols ${ }^{13,17}$.

Thus, the systematic and early documentation of cleft lip and palate individual should be emphasized considering that their rehabilitative treatment is a constant challenge and should be started at birth7. It is important to emphasize that the dental documentation provides an adequate and prospective planning, by individualizing the procedures required by each specific case, and allows evaluating longitudinally the progress reached in the proposed treatment.

Wutzl, et al. ${ }^{19}$ (2009) observed that prospective studies starting at birth are necessary to evaluate the treatment protocol and that dental casts are an important tool for documenting the original maxilla-tooth status. Many studies used maxillary arch dimensions and landmarks for analysis of the development and growth in patients with cleft lip and palate $3,4,10,13,16,19$. Landmarks analysis is a useful method for comparing the outcome of patients undergoing different treatment protocols. Landmarks on the dental casts of patients with cleft lip and palate are more difficult to find than those on the casts of non-cleft patients ${ }^{18}$.

Recently, the three-dimensional (3D) scanner was presented in literature as a tool for analysis of arch dimensions and landmarks on cleft lip and palate casts. It produces 3D data from the surface structures of the cast using scanning techniques. The potential benefit of this tool for landmark positioning and analysis is a matter of discussion ${ }^{2,6}$. Brief, et al. ${ }^{3}$ (2006) quantified the accuracy of landmark positioning on digitized casts using laser scanning of children with unilateral cleft lip and palate.

The digital casts provide a relationship with the craniofacial plane. The study of the dental arches of cleft lip and palate patients contributes for a better understanding of the morphological alterations of the dental arches, which can be useful in the preventive and corrective treatment of cleft lip and palate patients ${ }^{1,14,15}$.

The purpose of this present study was to compare, by means of 3D digital casts, the anterior transverse dimension of the dental arch in newborns with and without cleft lip and palate.

\section{MATERIAL AND METHODS}

The Ethical Committee in Research of the Hospital for the Rehabilitation of Craniofacial Anomalies of the University of São Paulo approved the protocol of this study (\#080/2012). The parents or guardians of the children received detailed information concerning the nature and the procedures involved in the study and signed informed consent forms.

The sample was composed of ninety-four children aged from 3 to 9 months, of both genders. Inclusion criteria included cleft lip and palate with or without Simonart band, without any associated syndrome or malformation and without previous surgery. The participants of the study were divided into three groups: Group I - children without craniofacial deformities $(n=19)$ (control group); Group II - children with unilateral cleft lip and palate (UCLP) $(n=50)$; Group III - children with bilateral cleft lip and palate (BCLP) $(n=25)$.

The selection of the children for the samples was performed according to each group. In Group I (Control), the participants were selected in the Discipline of Pediatric Dentistry of the Bauru School of Dentistry (FOB/USP), and in Groups II and III, at the Hospital for Rehabilitation of Craniofacial Anomalies (HRAC/USP).

The assessment was performed through dental casts of each patient by one investigator previously trained and calibrated. The measurements of the maxillary arches were obtained from the casts and used for correlation among groups. Next, data were recorded on specific charts for each patient. For that purpose, dental study casts were obtained after a reliable copy of the condensation silicon impression (Perfil, Vigodent, Rio de Janeiro, Brazil), aiming at reaching a perfect reproducibility of dental arches. The impression was executed through customized dental trays, properly selected, made directly in the mouth of the patient, prior to the primary surgeries.

The dental trays were customized and constructed in acrylic resin, with size compatible with the dental arch of the patients (Figure 1 ). To reach the best adaptation of the tray, dental periphery wax was

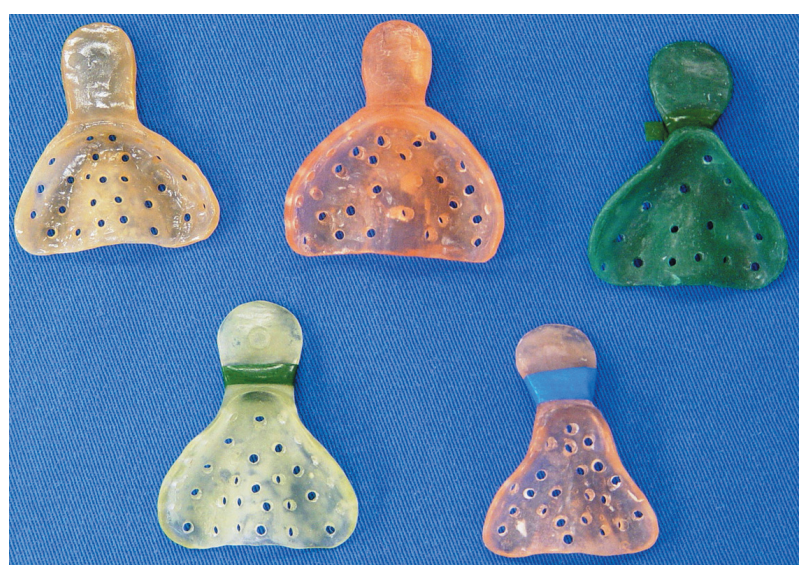

Figure 1- Customized trays constructed in acrylic resin for impressions of children at first ages 


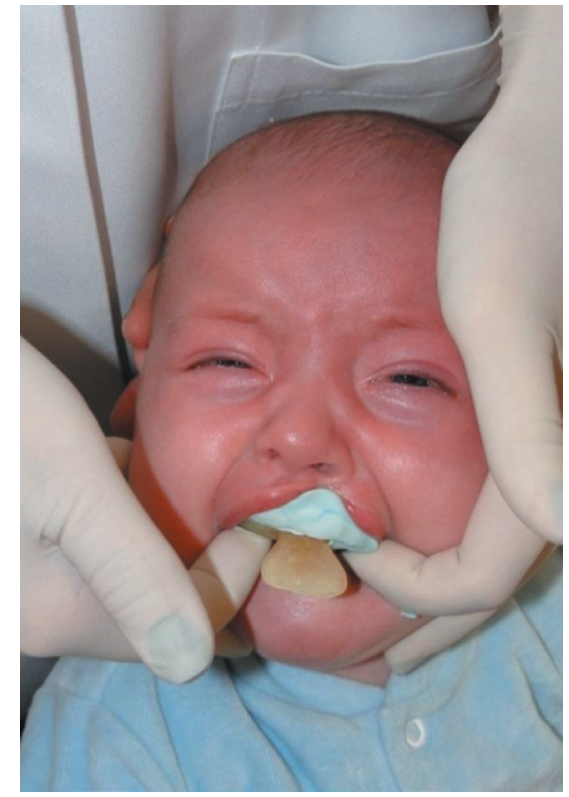

Figure 2- Child seated on the lap of the mother to perform the impression (parents signed informed consent authorizing the publication of this picture)

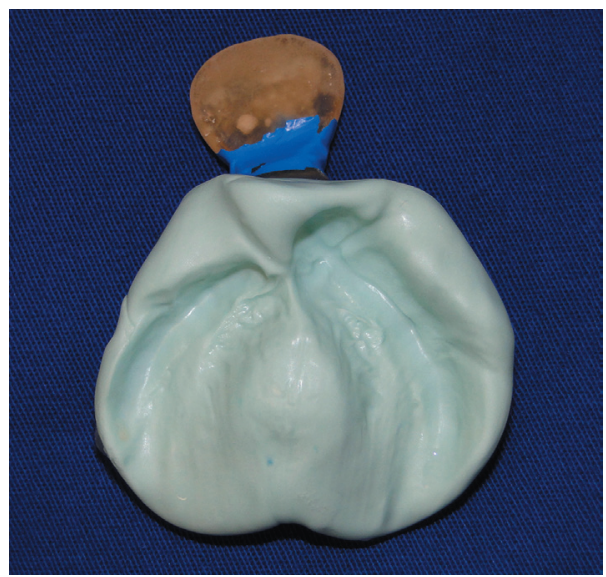

Figure 3- Impression of the maxillary dental arch comprising from the anterior border of the cleft to the retromolar region

used to seal the area of the bottom of the gingival sulcus. The next step was the manipulation of the impression material according to the instructions of the manufacturer. The mixing ratio was one scoop of base paste for two scoops of catalyst paste.

The impression was taken with the child seated on the lap of the mother to avoid that the hands of the newborns would touch the mouth. The examiner stood upright behind the patient (Figure 2 ). After the setting of the impression material, the tray was removed and the impression quality was verified. This should be perfect, comprising the anterior border of the cleft and the tuberosity



Figure 4- Study casts with standardized cuts proportional to the dental-alveolar areas

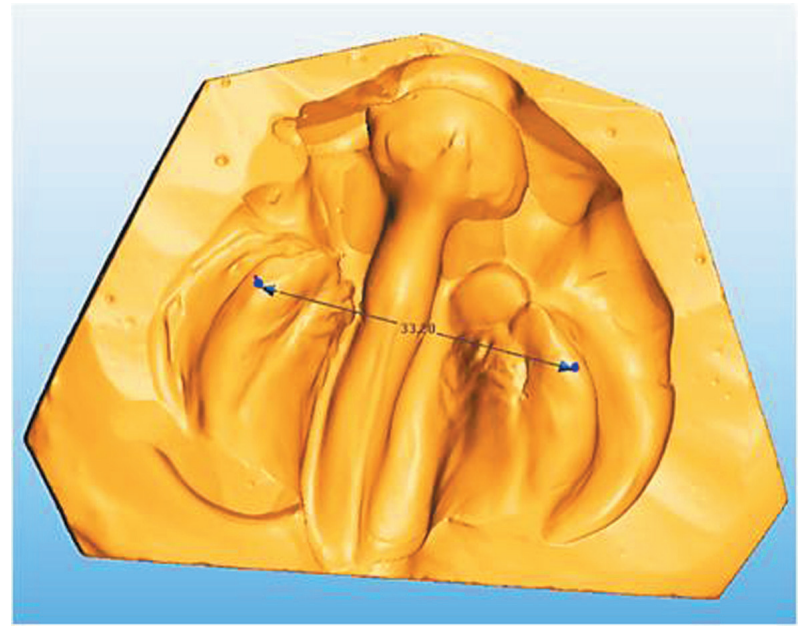

Figure 5- Screen of the computer showing the digitzed cast and the respective measurements

region, requiring deepness of the gingival sulcus, in all its extension (Figure 3 ).

Dental casts were constructed in white plaster (Figure 4). Following, the casts were cut aiming to obtain standardized bases proportional to the dental-alveolar areas. The casting of Group I (control group) was matched for age and the casts were as standardly obtained as those for the cleft lip and palate groups. Dental casts were digitized using a 3D Scanner (3Shape's R700'M Scanner, Copenhagen K, Denmark) linked to a computer. Next, the casts were reliably digitized and the obtained measurements were assessed through software (3D Software OrthoAnalyzer ${ }^{\mathrm{TM}}$, Copenhagen K, Denmark) (Figure 5).

The software reads the landmarks images (measuring points and lines) according to their Cartesian planes. Then, it unites these planes to generate measurements, which were executed directly on the scanner images. On the digital casts, the landmarks of the maxillary dental arches, required for the execution of the intercanine distance measurements ( $C$ and $C^{\prime}$ points), were 


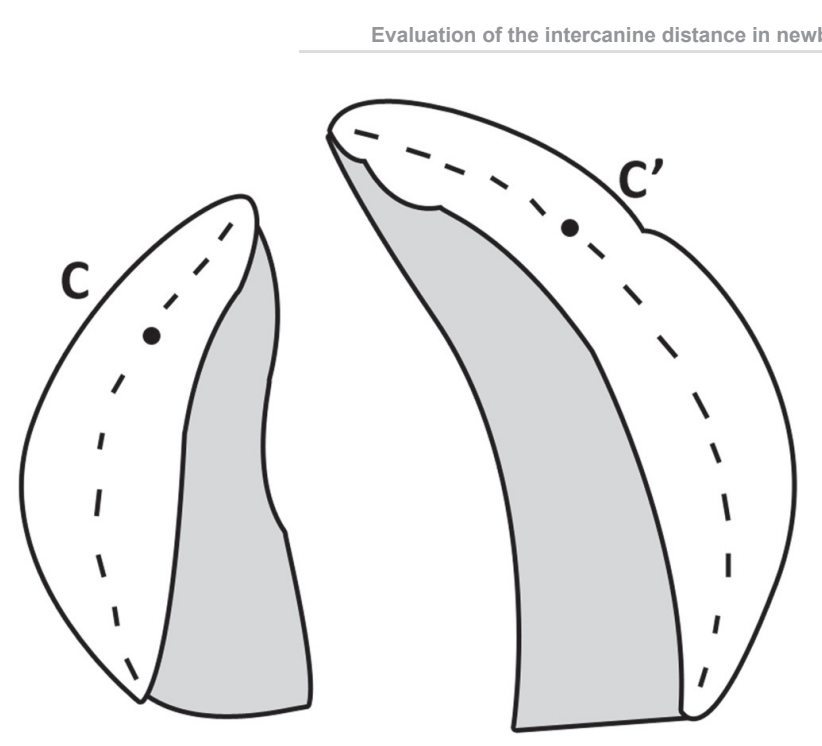

Figure 6- Canine landmarks in unilateral cleft lip and palate patients

defined according to those described by Seckel, et al. ${ }^{16}$ (1995) with some modifications (Figures 6 and 7).

The data were submitted to statistical analysis for comparison among groups after all impressions and measurements. Student t and Dahlberg's formula tests were applied to method error calculation. Data were submitted to repeated measures ANOVA and Tukey tests. The level of significance adopted was $5 \%$.

\section{RESULTS}

The results showed a mean of $36.5 \mathrm{~mm}$ for unilateral cleft lip and palate group, $34.8 \mathrm{~mm}$ for bilateral cleft lip and palate group and $27.52 \mathrm{~mm}$

Table 1- Measurements found in the studied groups

\begin{tabular}{lcc}
\hline & $\begin{array}{c}\text { Mean Intercanine } \\
\text { distance }(\mathbf{m m})\end{array}$ & $\begin{array}{c}\text { Standard } \\
\text { deviation }\end{array}$ \\
\hline Control $(\mathrm{n}=19)$ & 27.52 & 2.07 \\
$\operatorname{UCLP}(\mathrm{n}=50)$ & 36.50 & 3.66 \\
$\operatorname{BCLP}(\mathrm{n}=25)$ & 34.83 & 3.69 \\
\hline
\end{tabular}

UCLP=unilateral cleft lip and palate

$\mathrm{BCLP}=$ bilateral cleft lip and palate

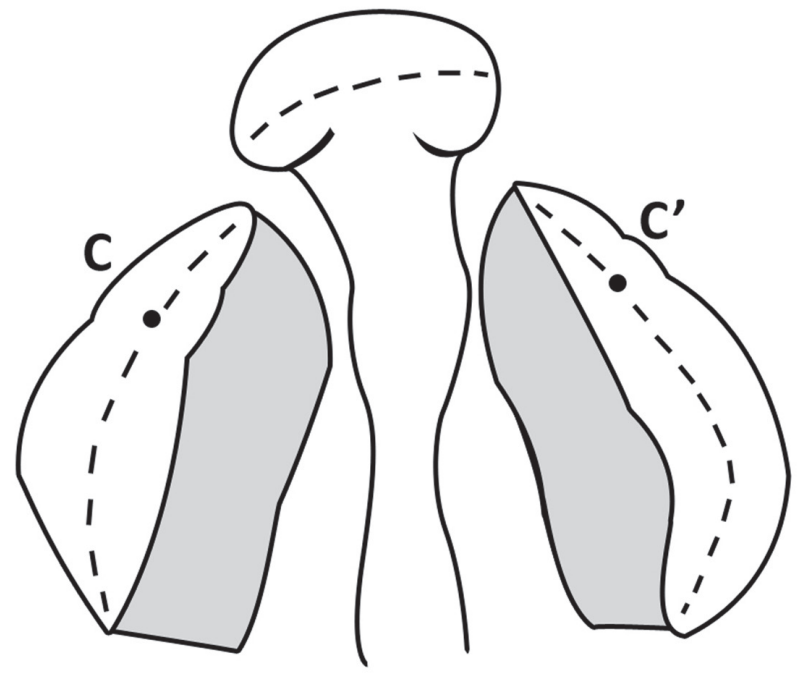

Figure 7- Canine landmarks in bilateral cleft lip and palate patients

for the control group (Table 1).

One examiner previously calibrated visually evaluated each image, after a 30-day interval between the assessments $(p=0.126)$. There was a statistically significant difference between the control group and both groups of patients with cleft lip and palate. There was no statistically significant difference between groups with complete unilateral and bilateral cleft lip and palate (Table 2).

\section{DISCUSSION}

The requirements of patients with cleft lip and palate extend beyond surgical repair. A multidisciplinary approach to the care of patients with cleft lip and palate is the widely accepted standard protocol in most regions of the developed world. However, the existing shortages of healthcare resources have precluded provision of the most basic care to patients with cleft lip and palate. Innovative technology applications may facilitate the performance of the evaluation of dental arch dimensions in these patients ${ }^{9}$.

Three-dimensional imaging of digital casts are increasingly gaining acceptance as an alternative to traditional plaster casts. The potential advantages of digital casts are reduced storage requirements,

Table 2- Results of $t$ test for the studied variables

\begin{tabular}{cccc}
\hline Groups & UCLP & BCLP & Control \\
\hline UCLP & - & 0.200 & $0.000106^{*}$ \\
BCLP & 0.200 & - & $0.000106^{*}$ \\
Control & $0.000106^{*}$ & $0.000106^{*}$ & - \\
\hline
\end{tabular}

*=statistically significant differences $(p<0.05)$

UCLP=unilateral cleft lip and palate

BCLP=bilateral cleft lip and palate 
rapid access to digital information and easy transfer of data, versatility and financial savings ${ }^{5}$. Compared with the physical plaster casts, the digital data are easier to store and they do not degrade ${ }^{11}$. In addition, scanners with a higher resolution will be able to produce digitized casts that give a more detailed resemblance of the original physical cast ${ }^{3}$. It has also become readily available to reproduce the physical casts from the archived 3D digital data using modern rapid prototyping technology ${ }^{11}$. In this investigation, we used digital models for evaluation of the dental arches measurements in newborns with cleft lip and palate.

This study measured the intercanine distance following the protocol by Seckel, et al. ${ }^{16}$ (1995) with some modifications. The intercanine distance measurement is very important to evaluate the treatment protocol for cleft lip and palate patients longitudinally. There is no such standard pattern for landmark positions on dental casts ${ }^{17}$. For this reason, we investigated the reliability and repeatability for both the observer and the measurements. The intra-observer measurements were calculated, the correction of the estimated difficulty of accuracy of the measurement determined and compared by method error. Seckel, et al. ${ }^{16}$ (1995) affirmed that the reproducible landmark positioning can only be a reality if the quality of the cast is optimal and the investigator is experienced and, even then, only for some of the landmarks investigated. Reproducibility might be enhanced by additional information from serial casts of the same individual. In the HRAC/ USP the casts are of great quality. Foong, et al. ${ }^{6}$ (1999) determined the reliability of the surface laser scanning technique and assessed the reliability of interactive 3D landmark localization. The clinical application of this technology in cleft lip and palate documentation requires validation of the technique. Original and duplicate plaster casts of an infant with a complete unilateral cleft lip and palate were digitized with a laser scanner. The authors concluded that landmarks well defined by a clearly visible visual cue on the 3D image were more reliable.

The methodology used in the present study evaluated a three-dimensional imaging method to measure 3 to 9 month-old unoperated patients with different types of cleft. Our data showed that bilateral cleft lip and palate and unilateral cleft lip and palate had significantly larger intercanine distance than control group. Other studies confirmed the difference between patients with and without cleft. Lo, et al. ${ }^{12}$ (2003), observed that bilateral and unilateral complete cleft lip and palate subjects had significantly smaller palatal surface area than both unilateral incomplete cleft lip and palate and cleft palate groups, which indicated a tissue deficiency. This intrinsic deficiency of the palatal surface is likely to become maxillary hypoplasia with the ongoing facial growth and development. The growth potential may further be impacted by surgical interventions with adverse iatrogenic consequence ${ }^{12}$. The great variability in cleft width, maxillary segment position and tissue deficiency within each cleft type also should be considered ${ }^{12}$.

The rehabilitative treatment following-up at early age has been little studied due to the difficulty in establishing a methodology enabling to access and analyze early-age patients without the involvement of ethical aspects which could justify the execution of the therapeutic procedures, mainly regarding children less than 5-years-old not presenting anatomical alterations in either the skull or face. Notwithstanding, the recording of these data is of extreme relevance to allow the establishment of normality patterns inside the Brazilian infant and adolescent population. Also, they can be compared with those of infant and adolescent population showing craniofacial anomalies. To enable methods of assessment and comparison of the diagnosis and treatment, it is necessary the assessment of normality conditions.

The impression procedure of children at early childhood has unique characteristics and it is rarely executed for growth documentation. In cleft lip and palate children, the impression is vital for the obtainment of the dental mold which will enable the conduction of important studies, assessments and explorations of the documentation for the adequate rehabilitation. The use of landmarks and tridimensional images for the study of dental arches has been a method largely employed for several aims: study of the maxillary growth and development; effects of the repair surgeries; and maxillary morphology alterations in cleft lip and palate patients. In the analysis of the results obtained, the intercanine distance of unilateral cleft lip and palate children was greater than that of Groups I and III. The intercanine means of Group II and III were very closer: $36.5 \mathrm{~mm}$ and 34.83 $\mathrm{mm}$, respectively, without statistically significant differences. There were statistically significant differences between the means of Group I (27.52 $\mathrm{mm}$ ) and those of the other two groups. This finding probably occurred because the palate of either bilateral or unilateral cleft lip and palate children, rather than that of the control groups, is compromised in both types of cleft, proving that the intercanine distance depends directly on the situation of the palate. This study was important to determine a treatment protocol for patients with cleft lip and palate. 


\section{CONCLUSION}

Patients with complete cleft lip and palate were born with an increased anterior dimension of the maxillary dental arch compared with non-cleft patients.

\section{REFERENCES}

1- Asquith JA, McIntyre GT. Dental arch relationships on threedimensional digital study models and conventional plaster study models for patients with unilateral cleft lip and palate. Cleft Palate Craniofac J. 2012;49(5):530-4.

2- Braumann B, Keilig L, Stellzig-Eisenhauer A, Bourauel C, Bergé $S$, Jager A. Patterns of maxillary alveolar arch growth changes of infants with unilateral cleft lip and palate: preliminary findings. Cleft Palate Craniofac J. 2003;40:363-72.

3- Brief J, Behle JH, Stellzig-Eisenhauer A, Hassfeld S. Precision of landmark positioning on digitized models from patients with cleft lip and palate. Cleft Palate Craniofac J. 2006;43(2):168-73. 4- Darvann TA, Hermann NV, Ersbøll BK, Kreiborg S, Berkowitz S. Palatal surface area of maxillary plaster casts - a comparison between two-dimensional and three-dimensional measurements. Cleft Palate Craniofac J. 2007;44(4):381-90.

5- Fleming PS, Marinho V, Johal A. Orthodontic measurements on digital study models compared with plaster models: a systematic review. Orthod Craniofac Res. 2011;14(1):1-16.

6- Foong KW, Sandham A, Ong SH, Wong CW, Wang Y, Kassim A. Surface laser scanning of the cleft palate deformity - validation of the method. Ann Acad Med Singapore. 1999;28:642-9.

7- Freitas JA, Garib DG, Oliveira TM, Lauris RC, Almeida AL, Neves $\mathrm{LT}$, et al. Rehabilitative treatment of cleft lip and palate: experience of the Hospital for Rehabilitation of Craniofacial Anomalies/USP (HRAC/USP) - Part 2: Pediatric Dentistry and Orthodontics. J Appl Oral Sci. 2012;20(2):268-81.

8- Freitas JA, Neves LT, Almeida AL, Garib DG, Trindade-Suedam IK, Yaedú RY, et al. Rehabilitative treatment of cleft lip and palate: experience of the Hospital for Rehabilitation of Craniofacial Anomalies/USP (HRAC/USP) - Part 1: overall aspects. J Appl Oral Sci. $2012 ; 20(1): 9-15$.
9- Furr MC, Larkin E, Blakeley R, Albert TW, Tsugawa L, Weber SM. Extending multidisciplinary management of cleft palate to the developing world. J Oral Maxillofac Surg. 2011;69(1):237-41. 10- Honda Y, Suzuki A, Ohishi M, Tashiro H. Longitudinal study on the changes of maxillary arch dimensions in Japanese children with cleft lip and/or palate: infancy to 4 years of age. Cleft Palate Craniofac J. 1995;32:149-55.

11- Lin CC, Lo LJ, Lee MY, Wong HF, Chen YR. Craniofacial surgical simulation: application of three-dimensional medical imaging and rapid prototyping models. Chang Gung Med J. 2001;24(4):229-38. 12- Lo LJ, Wong FH, Chen YR, Lin WY, Ko EW. Palatal surface area measurement: comparisons among different cleft types. Ann Plast Surg. 2003;50(1):18-23.

13- Long RE Jr, Hathaway R, Daskalogiannakis, Mercado A, Russel K, Cohen $M$, et al. The Americleft study: an inter-center study of treatment for patients with unilateral cleft lip and palate. Part 1: Principles and study design. Cleft Palate Craniofac J. 2011;48:239-43.

14- Peluso MJ, Josell SD, Levine SW, Lorei BJ. Digital models: an introduction. Semin Orthod. 2004;10:226-38.

15- Rheude B, Sadowsky PL, Ferriera A, Jacobson A. An evaluation of the use of digital study models in orthodontic diagnosis and treatment planning. Angle Orthod. 2005;75:300-4.

16- Seckel NG, van der Tweel I, Elema GA, Specken TF. Landmark positioning on maxilla of cleft lip and palate infant - a reality? Cleft Palate Craniofac J. 1995;32(5):434-41.

17- Semb G, Brattström V, Mølsted K, Prahl-Andersen B, Zuurbier $P$, Rumsey $N$, et al. The Eurocleft study: intercenter study of treatment outcome in patients with complete cleft lip and palate. Part 4: relationship among treatment outcome, patient/parent satisfaction, and the burden of care. Cleft Palate Craniofac J. 2005;42:83-92.

18- Shaw WC. Early orthopaedic treatment of unilateral cleft lip and palate. $\mathrm{Br}$ J Orthod. 1978;5(3):119-32.

19- Wutzl A, Sinko K, Shengelia N, Brozek W, Watzinger F, Schicho $\mathrm{K}$, et al. Examination of dental casts in newborns with bilateral complete cleft lip and palate. Int J Oral Maxillofac Surg. 2009;38(10):1025-9. 